\title{
Psych: An International, Open Access, Peer Reviewed Journal on Fields Ranging from Experimental Psychology to Clinical Psychiatry
}

\author{
Thomas E. Schläpfer \\ Department of Interventional Biological Psychiatry, University of Freiburg, Hauptstrasse 5, \\ 79085 Freiburg im Breisgau, Germany; thomas.schlaepfer@uniklinik-freiburg.de
}

Received: 2 July 2020; Accepted: 2 July 2020; Published: 3 July 2020

check for updates

\section{Scope}

It is with great honour and pleasure that I introduce, on behalf of the four Section Editors-in-Chief, the 53 members of the editorial board and the publisher MDPI, this journal. As stated, it is meant to be a broad journal encompassing neuroscience from Experimental Psychology to Clinical Psychiatry.

There are few areas of science where knowledge has grown so much-Both in breadth and depth-As in the neurosciences. In my own training as a clinical psychiatrist, I was taught in medicine, psychotherapy and psychopharmacology. Later on in my academic career, I had to grasp many disciplines my basic education had left me ill prepared for. At this time, it was believed by many educators that too much science would spoil the traits that define a good psychiatrist, and a virtual wall between clinical psychiatry and neurosciences existed. Recent advances in these sciences make it untenable at this time to know precisely where to draw the line between psychology, psychiatry and basic neuroscience. It has become very clear that only a deep and broad knowledge of all neuroscience will probably allow psychiatric disorders to be addressed-The impact of this insight has yet to have its full impact on education programs. The time is far gone where artificial boundaries between psychology and psychiatry would limit educated comprehensive understanding of the underlying neurobiology of disease and consequent treatments.

There are many specialized journals reflecting the extremely diverse fields contributing to the neurosciences. With the journal Psych, we intend to provide a platform with open access to foster crosstalk and interplay between different subfields of neuroscience.

\section{Editorial and Publication Processes and Peer Review}

The editorial process will be led by our colleagues at MDPI. They will distribute manuscripts for peer review and consult the relevant editors regarding the results of the reviews. We wish to monitor our editorial processes and to respond in a very timely fashion to editorial queries, to completing reviews, and to editorial decision-making.

Submitted manuscripts will be sent to two or three reviewers for comments pertaining to the importance of the manuscript, quality of the methods, and adequacy of the results and conclusions. We will also solicit comments on the adequacy of the references, utility of tables and figures, adequacy of the structured abstract and clarity of writing. The review process is critical to the scientific integrity of the discipline; reviewers should treat this responsibility with the upmost respect and empathy for authors. The editorial staff at MDPI and I hope to provide some information on how we are faring in our review and editorial decision-making processes in due course.

We are tremendously fortunate to have available the publishing experiences of the staff at MDPI. They will work to ensure timely reviews and editorial decision-making. Psych is strictly open access. This means that no reader will be charged for access to research published in the journal. The costs are 
covered through modest fees, which are consistent with those charged by other open access journals. These are paid only if the article is accepted. In addition, fees for the inaugural volume will be waived. Open access publishing prevents considerable publishing delays and the high institutional subscription prices that are common to scientific publishing.

Funding: This research received no external funding.

Conflicts of Interest: The author declares no conflict of interest.

(C) 2020 by the author. Licensee MDPI, Basel, Switzerland. This article is an open access article distributed under the terms and conditions of the Creative Commons Attribution (CC BY) license (http://creativecommons.org/licenses/by/4.0/). 